\title{
The Relationship between Introversion, Extraversion and Statuses in Cyberbullying among Teenagers in Bangkok
}

\author{
Prankit Siripichitsupapol $^{1}$, Pusanisa Muangwirot ${ }^{2}$, Nitchisa Ritprakongchao ${ }^{3}$ \\ ${ }^{1,2}$ Triam Udom Suksa School \\ ${ }^{3}$ Singapore International School of Bangkok
}

\begin{abstract}
Cyberbullying, a form of bullying with the use of digital technologies, has become increasingly common among teenagers. It can take place on social media, messaging platforms, gaming platforms, and previous studies provide several lines of evidence that no relationship is found between cyberbullying and the influences of introversion and extraversion. To further investigate the impact of cyberbullying, this research was conducted with the aim of finding relationship between introversion, extraversion and cyberbullying among teenagers in Bangkok, the capital city of Thailand. A cross-sectional study was conducted using an online survey questionnaire that contained questions for assessing both the cyberbullying behavior and the personality of participants. Eysenck's Personality Inventory (EPI) ${ }^{1}$ was used in this survey to assess the type of personality in teenagers. The results showed that there was no correlation between cyberbullying and personality.
\end{abstract}

KEYWORDS: Introversion, Extroversion, Cyberbullying

\section{INTRODUCTION}

Social media has contradictory sides with both positive and negative impacts on the users. It has become a huge part of today's internet which has altered the way people from all around the world communicate, work and live. Nowadays, people tend to depend on technology in order to gather information or effectively communicate with each other through various ways such as e-mail, Facebook, Instagram, etc. These forms of communication could potentially benefit us from saving a huge amount of time contacting others though it could also go the other way round. Although having these advancements may seem to be beneficial, they can lead to cyberbullying. Social media has resulted in people, particularly teenagers, using it as a platform to criticize others for the sake of personal entertainment or to express their true feelings towards a person in an unpleasant way through digital devices, which may lead to rapidly growing harmful behaviors of cyberbullying. Cyberbullying is a form of harassment ${ }^{2}$ through electronic devices with the aim of annoying, disturbing or irritating others, which can be both anonymous or not. The anonymity of cyberbullying has caused even more young adolescents to be experiencing hateful, antagonistic and hostile behaviors of people. These groups of people are classified into two groups including extroverts and introverts. Extroverts are generally defined as the one who is more socially-present, usually finding themselves as the center of attention ${ }^{3}$ while introverts tend to be quieter. There are many means to categorize participant roles in cyberbullying, but the most widely-accepted one was conducted by Salmivalli, et al (1996) ${ }^{3}$ which categorizes roles into 6 types. This research focused on 3 main categories: victim, bystander, and bully aggressor. Both introverts and extroverts could play a part in any role when it comes to cyberbullying: therefore, this study was carried out to examine the relationship between introvert students' role concerning cyberbullying and extrovert students' role. However, the result showed no correlation between being an introvert or extrovert and roles in cyberbullying.

\section{METHODOLOGY}

The questionnaire consisted of 24 questions, divided into two parts including Personality and Cyberbullying. The Personality test was derived from Eysenck's Personality Inventory (EPI) which has been developed by Eysenck and the Cyberbullying test was derived from Cyberbullying Assessment for Youth (CBAY) ${ }^{4}$ by Mendenhall and Barnett (2011). In cyberbullying questionnaires, there are 3 parts to determine respondents' role in cyberbullying: victim, bystander, bully aggressor. The questionnaires also include factors which may correlate with personalities or roles in cyberbullying. Purposive sampling was used in this research. The survey was distributed via online platforms (e.g. Line and Instagram) to teenagers in Bangkok in February 2021. After 134 responses were submitted, Microsoft Excel was used to perform analysis. The questionnaire contained a 5-point Likert scale ranking from strongly disagree to strongly agree. Each number is interpreted differently - $1=$ strongly disagree , $2=$ disagree, $3=$ neutral, $4=$ agree, $5=$ strongly 


\section{International Journal of Current Science Research and Review}

ISSN: 2581-8341

Volume 04 Issue 05 May 2021

DOI: 10.47191/ijcsrr/V4-i5-01, Impact Factor: 5.825

IJCSRR@ 2021

Www.ijesrr.org

agree. This questionnaire underwent Item-Objective Congruence (IOC) to be evaluated by 4 experts- only the items that had scores higher than 0.5 were accepted to be included in the questionnaire. Subsequent to that, the questionnaire underwent pilot testing to evaluate reliability in each question: questions with undesirable reliability score were excluded. Using Cronbach's alpha ${ }^{5}$, the reliability of this questionnaire is 0.776 .

\section{REVIEW OF LITERATURE}

Cyberbullying has been defined as behavior that is repetitive, aggressive, hurtful and intended to cause harm by creating power imbalance ${ }^{6}$.Unconsciously, cyberbullying has become a common phenomenon among teenagers. Several studies have shown that a number of students are victims of cyberbullying, which leads to a wider realization that cyberbullying is becoming a serious problem. Cyberbullying can be desolating for victims and their families. The psychological harm inflicted by cyberbullying is indicated in anger, anxiety, sadness, fear, depression, and suicide. Cyberbullying is a very difficult form to prevent and there is no flee for the victims. Many students who are victims of face-to-face harassment at school may also targeted in cyberspace. Moreover, many people choose to bully others on the internet instead of the real world because they believe that the digital world is a place that they can hide their identities, or a place that bullying is acceptable ${ }^{7}$.

According to [Bystanders' behaviors and associated factors in cyberbullying], participants who either were victims of cyberbullying or knew of cyberbullying happening to friends or acquaintances and had high parental attachment would intervene more than those who never had such experiences. Participants who knew of cyberbullying happening to the general public had propensities towards ignoring the cyberbullying. Participants who had positive attitude towards joining in tended to partake in the cyberbullying more than those who were not.

Willard (2007a) identified two types of bystanders ${ }^{8}$, helpful bystanders and harmful bystanders. Helpful bystanders are individuals who proceed to stop the bully by either reporting the incident to an adult, by protesting against the bullying, or by providing help and support to the victim. Hurtful bystanders, in contrast, are involved either by supporting and instigating the bullying or by doing nothing to intervene or to assist the victim.

\section{RESEARCH QUESTIONS}

1) Are there any statistical correlations between the three roles of cyberbullying?

2) Are there any statistical correlations between personality types and the three roles of cyberbullying?

\section{DATA ANALYSIS}

The Statistical Product and Service Solutions version 27.0 (SPSS) was used to evaluate and improve the reliability score of each question. Then, Microsoft Excel was used to determine the correlation and also compare effects of different personalities to roles of cyberbullying all of the survey responses with each consisting of 5 choices according to the five-point Likert scale. Raw information was evaluated differently to be numerical value. To determine correlation between personality trait and opinion toward cyberbullying from respondents, Pearson's correlation test was applied, the result of which was exhibited in Table 4. On top of that, in order to determine whether different personalities had significant correlation to roles of cyberbullying or not, we use t-test to compare and contrast these two categories. Ultimately, the criteria ${ }^{9}$ used to determine the degree of correlation is exhibited in table below

Table illustrating how correlation coefficient is interpreted

\begin{tabular}{|l|l|}
\hline Size of Correlation & Interpretation \\
\hline .90 to $1.00(-.90$ to -1.00$)$ & Very high positive (negative) correlation \\
\hline .70 to $.90(-.70$ to -.90$)$ & High positive (negative) correlation \\
\hline .50 to $.70(-.50$ to -.70$)$ & Moderate positive (negative) correlation \\
\hline .30 to $.50(-.30$ to -.50$)$ & Low positive (negative) correlation \\
\hline .00 to $.30(.00$ to -.30$)$ & Negligible correlation \\
\hline
\end{tabular}




\section{International Journal of Current Science Research and Review}

ISSN: 2581-8341

Volume 04 Issue 05 May 2021

DOI: 10.47191/ijesrr/V4-i5-01, Impact Factor: 5.825

IJCSRR@ 2021

www.ijjesrr.org

\section{RESULTS}

Table 1: The number and percentage of samples regarding participants' personal information: gender and age. $(\mathrm{n}=134)$

\begin{tabular}{|l|l|l|}
\hline Personal Information & Frequency & Percentage \\
\hline 1) Gender & & \\
Female & 95 & 70.9 \\
Male & 31 & $\begin{array}{l}23.1 \\
\text { Others }\end{array}$ \\
\hline Total & 8 & 6 \\
\hline 2) Age & 134 & 100 \\
\hline Less than 15 years old & & \\
$15-18$ years old & 4 & 3 \\
$19-25$ years old & 108 & 80.6 \\
& 22 & 16.4 \\
\hline Total & 134 & 100 \\
\hline
\end{tabular}

According to table 1, the majority of samples was female, consisting of 95 people, accounting for $70.9 \%$. Most of the respondents are between 15 and 18 years old, consisting of 108 people, accounting for $80.6 \%$.

Table 2: Descriptive Statistics $(\mathrm{n}=134)$

\begin{tabular}{|l|l|l|l|}
\hline & Mean rating (out of 5) & Standard Deviation & N \\
\hline Personality & 2.91 & 0.43 & 134 \\
\hline Victim & 1.54 & 0.62 & 134 \\
\hline Bystander & 3.02 & 1.03 & 134 \\
\hline Aggressor & 1.81 & 0.60 & 134 \\
\hline
\end{tabular}

According to table 2, the greatest mean score was found in the group of bystander, accounted for 3.02 which is in the level of neutral view. Meanwhile, that in the group of victim and aggressor are 1.54 and 1.81 respectively which is in the level of disagreement.

Table 3: T-test

\begin{tabular}{|l|l|l|l|}
\hline \multirow{2}{*}{} & \multicolumn{2}{|l|}{ Mean rating(out of 5) } & \multirow{2}{*}{ P-value } \\
\cline { 2 - 3 } & Introvert & Extrovert & \\
\hline Victimization & 1.59 & 1.47 & 0.14 \\
\hline Bystander & 2.96 & 3.10 & 0.23 \\
\hline Bully aggressor & 1.81 & 1.80 & 0.47 \\
\hline
\end{tabular}




\section{International Journal of Current Science Research and Review}

ISSN: 2581-8341

Volume 04 Issue 05 May 2021

DOI: 10.47191/ijcsrr/V4-i5-01, Impact Factor: 5.825

IJCSRR@ 2021

WwW.ijcsrr.org

The mean score of bystander gained from those being classified as introverts was 2.96 which was lower than that of extroverts (3.10). However, the significance level indicates that this difference is not statistically significant. Likewise, no significance is found between introverts being victims or aggressors and extroverts being victims or aggressors.

Table 4: Level of disagreement towards roles of cyberbullying

\begin{tabular}{|l|l|l|}
\hline & Bystander & Bully aggressor \\
\hline Victimization & 0.00 & 0.00 \\
\hline Bystander & & 0.00 \\
\hline Bully aggressor & & \\
\hline
\end{tabular}

Table 5: The correlation test between personality, roles in cyberbullying, and other factors

\begin{tabular}{|l|l|l|l|l|}
\hline & Bystander & aggressor & personality & school rule \\
\hline Victim & -0.071 & 0.50 & -0.17 & 0.30 \\
\hline Bystander & & -0.13 & 0.060 & -0.13 \\
\hline Aggressor & & & -0.025 & 0.22 \\
\hline Personality & & & & -0.091 \\
\hline
\end{tabular}

According to the correlation test performed on the personality and roles in cyberbullying, there is a slight correlation between school administrators enforcing the code of conduct against cyberbullying and victimization ( 0.30$)$, and also correlation between victim and aggressor (0.50). Surprisingly, the results showed that there is no correlation between personality and roles in cyberbullying

\section{DISCUSSION}

According to the responses submitted via Google Form, 78 people were considered introvert, while 56 people were considered extrovert. The findings suggested that there was no significant correlation between personalities and roles of cyberbullying. This could be due to the fact that individuals may express their thought differently when they are behind the screen. Thus, no matter what personalities ones genuinely are, other online users may be mistaken by what they perceive on the internet.

This research study was similar to the previous study conducted by Dr. Rosemary V. Barnett $(2012)^{10}$ which concluded that there was no significant correlation between personality traits and roles in cyberbullying. The previous research focused on those in a small private school which may have effective interventions to tackle cyberbullying problems. However, this study focused on a small and nonspecific group of teenagers. Thus, we were unable to normalize this result to teenagers on a national scale.

Of the 134 responses, even though most of them disagree with victimizations and bully aggression, they do have neutral perspective toward being bystanders. This is the case because people who knew that cyberbullying happen in public tend to ignore more often than those who did not experience these perceptions ${ }^{11}$. This contributes to bystander effect which ,then, lead to moral disengagement ${ }^{12}$. Doing so mean they let cyberbullying continue. Moreover, online contact also increases the likelihood of negative bystander behaviors ${ }^{13}$.

Surprisingly, there was a moderate positive correlation between one being a victim and being an aggressor. Although the finding did not show any causation between the two, there had been research ${ }^{14}$ which suggest that children having exposed to bullying before are at high risk commit the same to others.

Moreover, the results showed that there was a moderate correlation between the existence of code of conduct against cyberbullying in school and cyberbullying victimizations. There has been research ${ }^{15}$ pointing out that the existence of school rules to protect students from being bullied is pointless and unsuccessful. 


\section{International Journal of Current Science Research and Review}

ISSN: 2581-8341

Volume 04 Issue 05 May 2021

DOI: 10.47191/ijcsrr/V4-i5-01, Impact Factor: 5.825

IJCSRR@ 2021

WwW.ijesrr.org

\section{CONCLUSION}

This research paper aims to find the correlation between personality and roles of cyberbullying. According to the finding, the correlation was close to zero and t-test showed no significance which revealed that there is no correlation between roles in cyberbullying among introverts and extraversions. This means no matter what personality individuals are, they can appear to play any role in cyberbullying. Major limitations of this study that has led to our responses being not as strong may include participants not realizing that they have been targeted to be victims of cyberbullying, they have been cyberbullied once and think that it is unnecessary to report it, or they misunderstood the questionnaires may perhaps lead our result being close to neutral.

\section{ACKNOWLEDGEMENT}

Special thanks are given to Assistant Professor Dr. Pratchayapong Yasri from the Institute for Innovative Learning, Mahodol University who supervised this work

\section{REFERENCES}

1. Rocklin T, Revelle W. The measurement of extroversion: A comparison of the Eysenck Personality Inventory and the Eysenck Personality Questionnaire. British Journal of Social Psychology. 1981 Nov;20(4):279-84.

2. Menesini E, Nocentini A. Cyberbullying definition and measurement: Some critical considerations. Zeitschrift für Psychologie/Journal of Psychology. 2009 Jan;217(4):230-2.

3. Salmivalli C, Lagerspetz K, Björkqvist K, Österman K, Kaukiainen A. Bullying as a group process: Participant roles and their relations to social status within the group. Aggressive Behavior: Official Journal of the International Society for Research on Aggression. 1996;22(1):1-5.

4. Mendenhall, E. \& Barnett, R. V., Cyberbullying Assessment for Youth. 2011.

5. Cortina JM. What is coefficient alpha? An examination of theory and applications. Journal of applied psychology. 1993 Feb;78(1):98.

6. Dehue, 2013; Langos, 2012; Vandebosch \& Van Cleemput, 2008).

7. Willard, N. (2005). Educator's guide to cyberbullying and cyberthreats. Center for Safe and Responsible Use of the Internet

8. Beran, T., \& Li, Q. (2005). Cyber-harassment: A new method for an old behaviour. Journal of Educational Computing Research

9. Mukaka MM. A guide to appropriate use of correlation coefficient in medical research. Malawi medical journal. 2012;24(3):69-71.

10. Barnett VR, Mendenhall E. Cyberbullying and the influences of Introversion and Extraversion According to the influences of Psychological Type. 2012.

11. Panumaporn J, Hongsanguansri S, Atsariyasing W, Kiatrungrit K. Bystanders' behaviours and associated factors in cyberbullying. General psychiatry. 2020;33(3).

12. Song J, Oh I. Factors influencing bystanders' behavioral reactions in cyberbullying situations. Computers in Human Behavior. 2018 Jan 1;78:273-82.

13. Barlińska J, Szuster A, Winiewski M. Cyberbullying among adolescent bystanders: Role of the communication medium, form of violence, and empathy. Journal of Community \& Applied Social Psychology. 2013 Jan;23(1):37-51.

14. Widom CS. The cycle of violence. Science. 1989 Apr 14;244(4901):160-6.

15. Schreck CJ, Miller JM, Gibson CL. Trouble in the school yard: A study of the risk factors of victimization at school. Crime \& Delinquency. 2003 Jul;49(3):460-84.

Cite this Article: Prankit Siripichitsupapol, Pusanisa Muangwirot, Nitchisa Ritprakongchao (2021). The Relationship between Introversion, Extraversion and Statuses in Cyberbullying among Teenagers in Bangkok. International Journal of Current Science Research and Review, 4(5), 328-332 